\title{
Tsunami Generation of the 1993 Hokkaido Nansei-Oki Earthquake
}

\author{
Kenji SATAKE ${ }^{l}$ and YuICHIRo TANIOKA ${ }^{1}$
}

\begin{abstract}
Heterogeneous fault motion of the 1993 Hokkaido Nansei-Oki earthquake is studied by using seismic, geodetic and tsunami data, and the tsunami generation from the fault model is examined. Seismological analyses indicate that the focal mechanism of the first $10 \mathrm{~s}$, when about a third of the total moment was released, is different from the overall focal mechanism. A joint inversion of geodetic data on Okushiri Island and the tide gauge records in Japan and Korea indicates that the largest slip, about $6 \mathrm{~m}$, occurred in a small area just south of the epicenter. This corresponds to the initial rupture on a fault plane dipping shallowly to the west. The slip on the northernmost subfault, which is dipping to the east, is about $2 \mathrm{~m}$, while the slips on the southern subfaults, which are steeply dipping to the west, are more than $3 \mathrm{~m}$. Tsunami heights around Okushiri Island are calculated from the heterogeneous fault model using different grid sizes. Computation on the smaller grids produces larger tsunami heights that are closer to the observed tsunami runup heights. Tsunami propagation in the nearly closed Japan Sea is examined as the free oscillation of the Japan Sea. The excitation of the free oscillation by this earthquake is smaller than that by the 1964 Niigata or 1983 Japan Sea earthquake.
\end{abstract}

Key words: Tsunamis, 1993 Hokkaido Nansei-Oki earthquake, Okushiri Island.

\section{Introduction}

The Hokkaido Nansei-Oki (southwest off Hokkaido) earthquake of July 12, 1993 generated devastating tsunamis that caused significant damage in Japan, particularly on Okushiri Island. The death total (including those still missing) was 230 and the damage totaled 1.2 billion U.S. dollars (IsHIYAMA, 1994). This earthquake was recorded on seismograms worldwide. The tsunamis were recorded on many tide gauges around the Japan Sea, including several in Korea. In addition to these instrumental data, extensive measurements were made on Okushiri Island for tsunami runup heights and crustal deformation. These surveys (e.g., HoKKAIDO Tsunami Survey Group, 1993; Kumaki et al., 1993; TSUTSum et al., 1993; Shuto and MATSUTOMI, 1995), show that the maximum tsunami runup height was $32 \mathrm{~m}$ on Okushiri Island and that the entire island subsided by $5-80 \mathrm{~cm}$.

Along the eastern margin of the Japan Sea (Figure 1), other earthquakes with a similar size have occurred in this century (FUKAO and Furumcto, 1975;

\footnotetext{
${ }^{1}$ Department of Geological Sciences, University of Michigan, Ann Arbor, MI 48109-1063, U.S.A.
} 


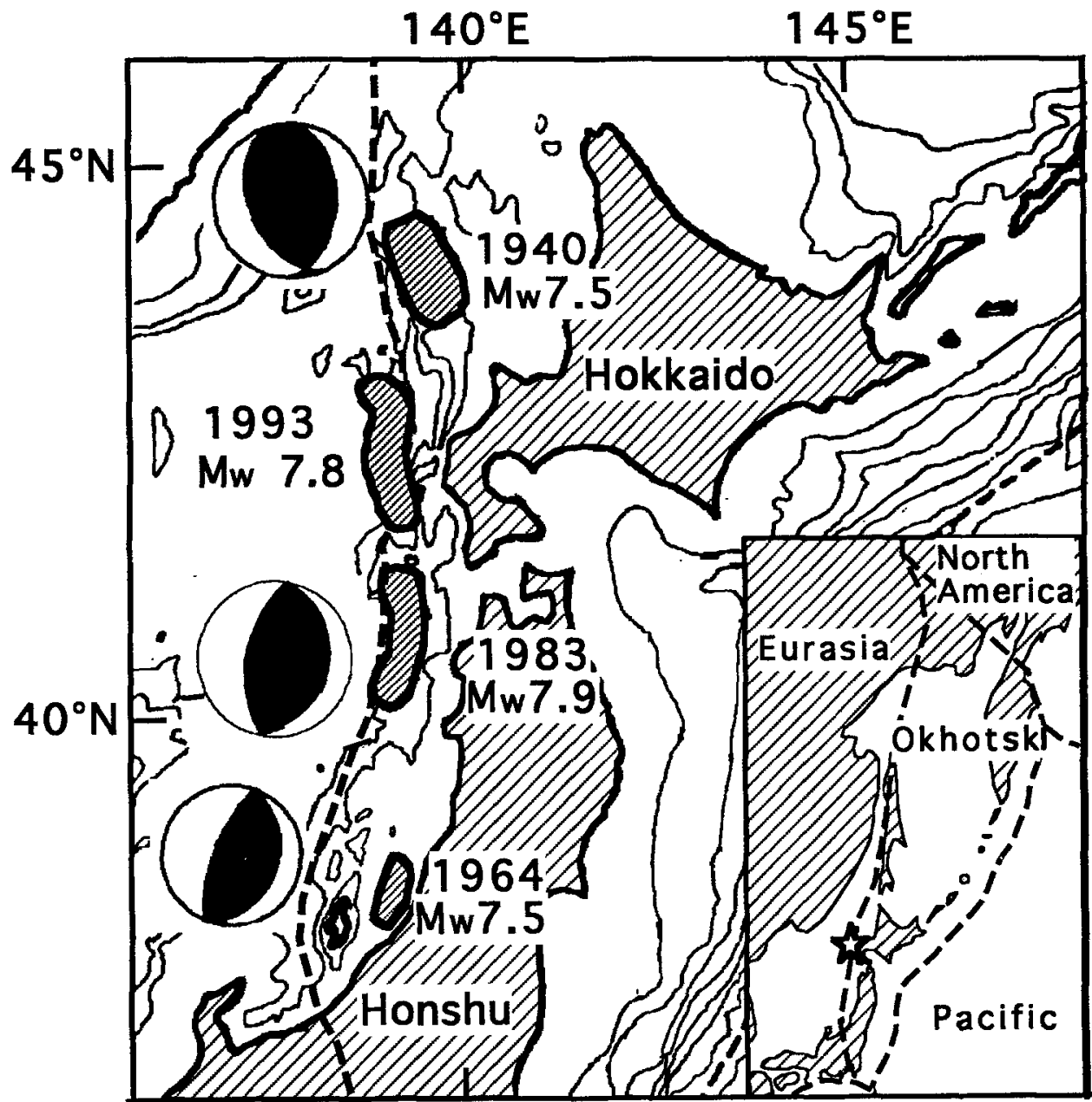

Figure 1

The source regions and focal mechanisms of the earthquakes along the eastern margin of the Japan Sea. Plate boundaries in the region are shown in the inset map.

SATAKE, 1986). They are the 1940 Shakotan-oki $\left(M_{w}, 7.5\right), 1964$ Niigata $\left(M_{w}, 7.5\right)$, and 1983 Japan Sea $\left(M_{w}, 7.9\right)$ earthquakes. Because of the semi-periodic occurrence of large earthquakes and geological background, it has been proposed in the last decade (NAKAMURA, 1983; KoBAyASHI, 1983) that the boundary between the North American and Eurasian plates has moved to the eastern margin of the Japan Sea in the last 1-2 Ma. A more recent model introduces another plate, the Okhotsk plate, and argues that the eastern margin of the Japan Sea is a convergent boundary between the Eurasian and Okhotsk plates (SENO and SAKURAI, 1993).

In this paper, we estimate the heterogeneous fault motion of the 1993 Hokkaido Nansei-Oki earthquake and examine the tsunami generation from the fault model. 
We first summarize the seismological analyses in Section 2. After we describe the tsunami and geodetic observations in Section 3, we perform inversions of tsunami and geodetic data in Section 4 to estimate the slip, or moment, distribution on the fault. The tsunami heights around Okushiri Island are computed using different grid sizes and are compared with the observed runup heights in Section 5. In Section 6, the tsunami generation is discussed from the viewpoint of free oscillation of the Japan Sea. The excitation coefficients are computed from the fault model and compared with those from other tsunami events in the Japan Sea.

\section{Seismological Analyses}

\subsection{Analyses of Global Data}

The Hokkaido Nansei-Oki earthquake occurred at $13 \mathrm{~h} 17 \mathrm{~m} 11.9 \mathrm{~s}$ on July 12 (GMT). The epicenter is $42.851^{\circ} \mathrm{N}, 139.197^{\circ} \mathrm{E}$ and the surface wave magnitude $\left(M_{s}\right)$ is 7.6, according to the National Earthquake Information Service. The moment tensor solutions were estimated by Harvard University (DZIEWONSKI et al., 1994) and the USGS (SIPKIN, 1994). The former uses long-period waves whereas the latter uses shorter-period body waves. Both show a reverse fault with the strike approximately in the $\mathrm{N}-\mathrm{S}$ direction. However, the dip angles were quite different. The Harvard CMT solution shows that the fault plane is either shallowly (with a dip angle of $35^{\circ}$ ) dipping to the east or steeply $\left(55^{\circ}\right)$ dipping to the west. The USGS solution, on the other hand, shows a shallowly $\left(39^{\circ}\right)$ dipping plane to the west and a steeply $\left(60^{\circ}\right)$ dipping plane to the east. The seismic moment estimates are also different; the Harvard CMT solution gives $4.7 \times 10^{20} \mathrm{Nm}$, while the USGS solution is $1.1 \times 10^{20} \mathrm{Nm}$.

Because of these discrepancies, we independently performed both CMT and body wave inversions (TANIOKA et al., 1995). The inversion of teleseismic body waves for Moment Tensor Rate Functions (MTRF inversion) exhibits a similar focal mechanism to that obtained by the USGS; a shallow $\left(24^{\circ}\right)$ dipping plane to the west and steeply $\left(66^{\circ}\right)$ dipping plane to the east. The first motions on global seismic networks are also consistent with this focal mechanism. The moment rate function, or the source time function, shows that about $2 \times 10^{20} \mathrm{Nm}$ of the moment was released within the first $10 \mathrm{~s}$, followed by a continuing moment release up to 1 min. Using this time function as the Green's function, we performed the CMT inversion. The result is still very similar to the Harvard solution; a shallowly $\left(32^{\circ}\right)$ dipping plane to the east and a steeply $\left(63^{\circ}\right)$ dipping plane to the west, and the total seismic moment is $5.5 \times 10^{20} \mathrm{Nm}$.

The CMT solution represents an average picture of focal mechanism and seismic moment, whereas the MTRF solution from body waves represents an initial rupture. The comparison indicates that about a third of the total seismic moment 
was released in the first $10 \mathrm{~s}$ with a somewhat different focal mechanism (TANIOKA et al., 1993).

\subsection{Analysis of Local Data}

The aftershock distribution has been determined by KASAHARA et al. (1994) and shown in Figure 2. The figure shows the epicenters of aftershocks that occurred within 5 months of the main shock. The aftershocks plotted in Figure 2 were all recorded at a station on Okushiri Island and relatively well-located. Nevertheless, the absolute depth may not be well constrained because of poor station distribution and incomplete knowledge of the velocity structure. The dip angle of fault plane is therefore more reliably estimated from focal mechanism studies; the aftershock distribution facilitates our choice of the actual fault plane from the two nodal planes.

The panels on the right in Figure 2 show the cross sections of the aftershock distribution. We will mostly focus on the upper edge of the aftershock clusters. In the northernmost section (A), the distribution shows a planar structure dipping to the east. Along the next two sections ( $B$ and $C$ ), the clusters, particularly the upper

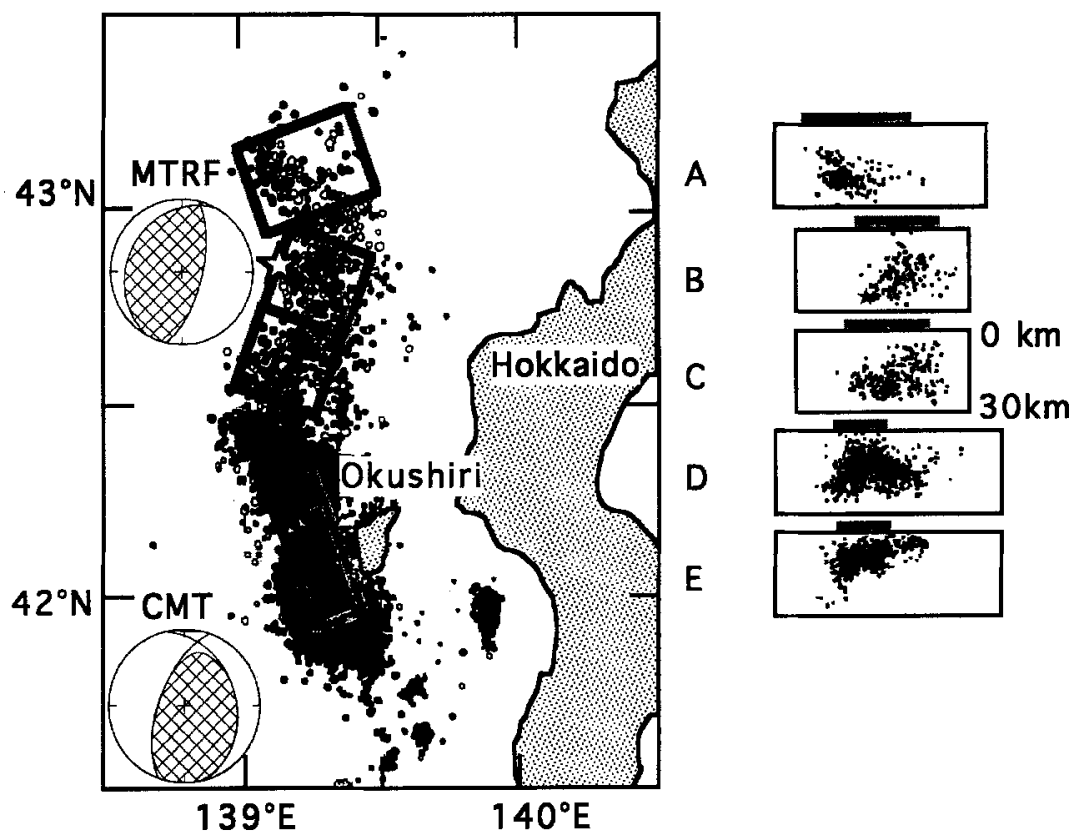

Figure 2

The aftershock distribution determined by KASAHARA et al. (1994). Frames in the map show the projections of subfaults that are used for the inversion. Panels in the right show the cross sections perpendicular to the strike of the subfaults. The shaded box indicates the projection of the subfaults.

Two focal mechanism solutions are also shown. Star indicates the hypocenter of the main shock. 
edge, seem to be dipping to the west, although it is less clear than section A. Along the southern two sections (D and E), it is more difficult to judge the orientation of the fault plane. In particular, along section $\mathrm{D}$, two planes, one shallowly dipping to the east and the other steeply dipping to the west, may be identified.

The two focal mechanism solutions are also shown in Figure 2. As mentioned above, the MTRF solution represents the focal mechanism of the first $10 \mathrm{~s}$ of rupture, presumably near the epicenter (in section B). The aftershock distribution suggests that the shallowly $\left(24^{\circ}\right)$ dipping plane to the west is the actual fault plane.

\section{Tsunami and Geodetic Observations}

\subsection{Tsunamis on Tide Gauges}

Tsunamis from the Hokkaido Nansei-Oki earthquake were recorded on many tide gauge stations in Japan and Korea. Figure 3 displays the locations of tide

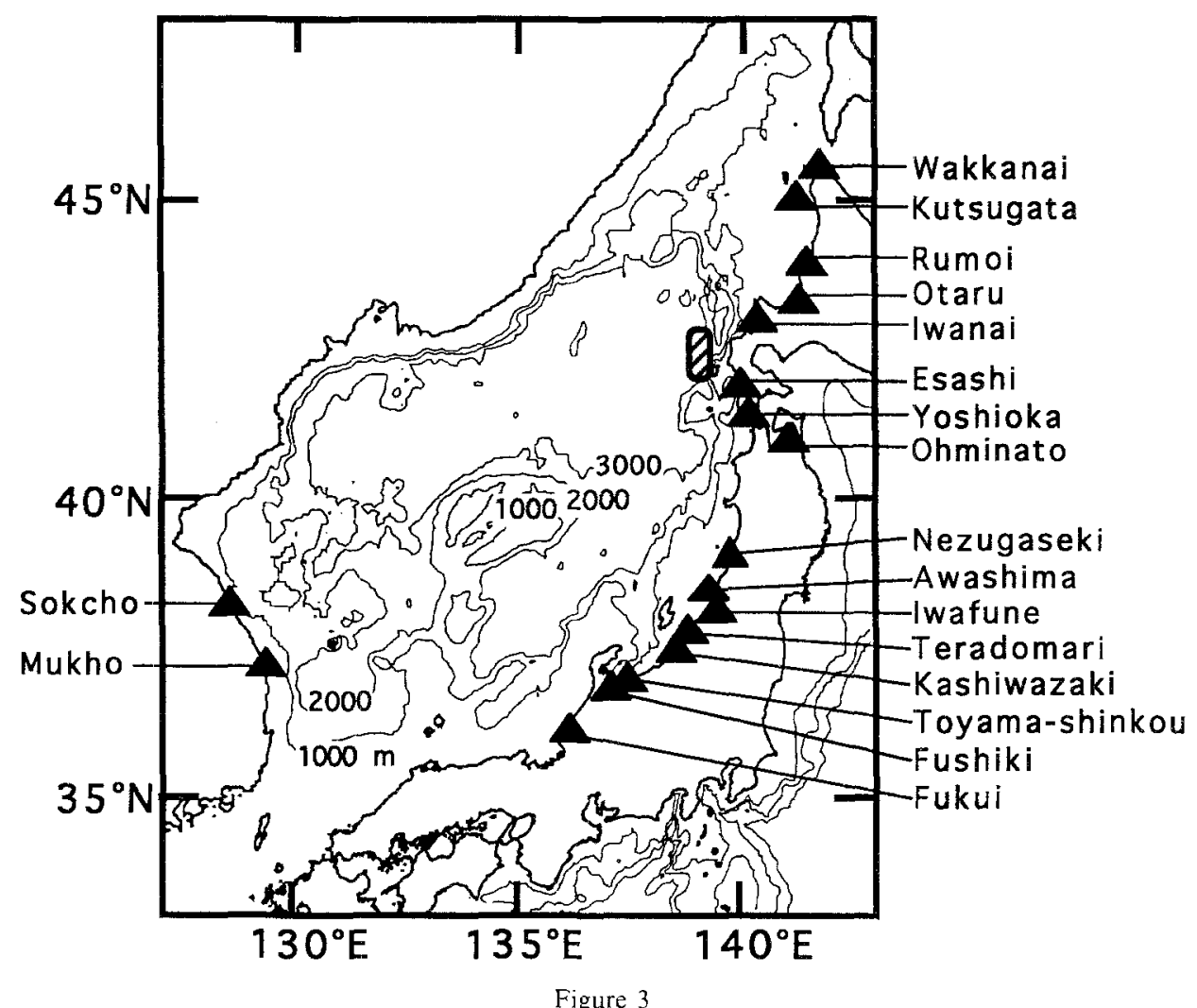

The location of the 1993 tsunami source and the tide gauge stations (solid triangles) used in this study. The map also shows the tsunami computational area and the bathymetry. 


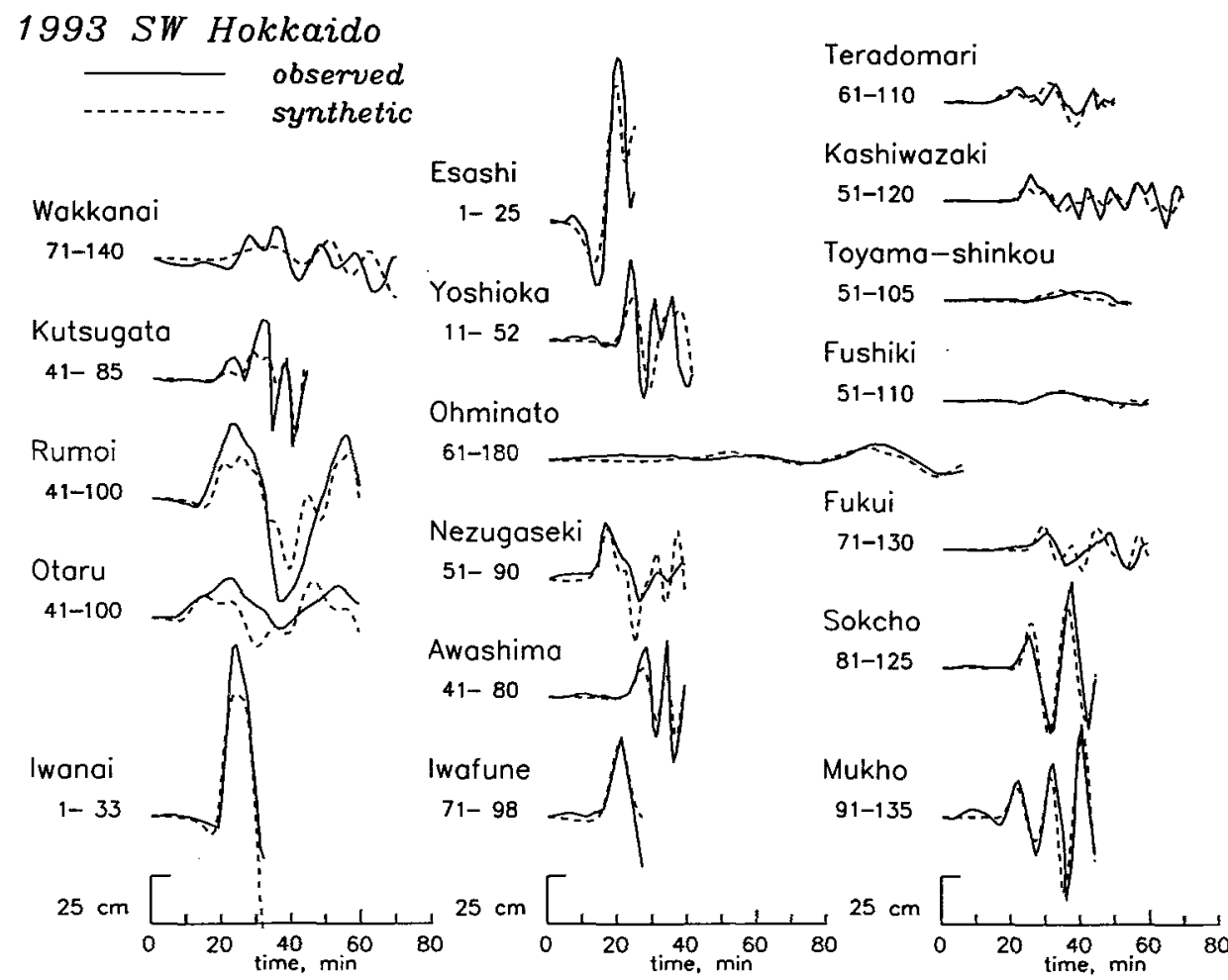

Figure 4

The observed tsunami waveforms (solid curves) compared with the computed ones (dashed curves) from the heterogeneous slip distribution estimated in this study. The time range of the waveform in min from the earthquake origin time is shown below the station name. For example, the Wakkanai record starts at $71 \mathrm{~min}$ after the origin time.

gauge stations we used in our analysis. The tsunami waveforms are shown in Figure 4. The closest tide gauge stations to the source area are Iwanai to the north and Esashi to the south. There was no station on Okushiri Island. At Iwanai, the sea level first fell about $12 \mathrm{~min}$ after the earthquake (the ground shaking due to the earthquake was recorded on the tide gauge) and a sharp rise started at about $20 \mathrm{~min}$. The amplitude of the first fall was $6 \mathrm{~cm}$ and the following rise was about $1 \mathrm{~m}$. The maximum amplitude $(140 \mathrm{~cm})$ was registered in the next cycle at about $55 \mathrm{~min}$ after the earthquake. At Esashi, the first fall of water level started at $10 \mathrm{~min}$ after the earthquake (the ground shaking was also recorded at this station) and the amplitude was about $34 \mathrm{~cm}$. The amplitude of the following peak is $90 \mathrm{~cm}$. After another peak, the gauge went off-scale. Tsunamis are recorded at other stations with smaller amplitudes (Figure 4). The tsunamis arrived at Korean tide gauge stations $100-110 \mathrm{~min}$ after the event with amplitudes of more than $1 \mathrm{~m}$. 


\subsection{Tsunami Runup Data}

The tsunami runup heights were extensively measured on Okushiri Island and the Hokkaido and Honshu coasts. On Okushiri Island, the largest tsunami runup was $32 \mathrm{~m}$, recorded in a small valley near Monai. The average runup height is more than $10 \mathrm{~m}$ in the southern half of the island, while it is much less than $10 \mathrm{~m}$ in the northern half. The detailed survey report can be found in HoKkaIDo TSUNAMI Survey Group (1993) and Shuto and Matsutomi (1995). We will later compare the calculated tsunami heights with the observed runup heights.

\subsection{Geodetic Data}

Subsidence of Okushiri Island has been measured by various methods. TSUTSUMI et al. (1993) performed continuous measurements of the water level at several harbors and estimated the water levels, consequently the ground heights, after the earthquake. Comparison of these heights with leveling data before the earthquake revealed the subsidence amounts with errors smaller than $5 \mathrm{~cm}$. KUMAKI et al. (1993) made similar estimates on coastal constructions such as breakwaters. They also made GPS measurements. These data are compiled in Figure 5. The amount of subsidence is smaller at the northeastern end of the island (smallest $5 \mathrm{~cm}$, but mostly about $20 \mathrm{~cm}$ ) and larger at the southwestern end (about $80 \mathrm{~cm}$ ). The island, as a whole, had tilted to the west.

\section{Inversions of Geodetic and Tsunami Data}

\subsection{Method}

Among the various fault parameters such as size and geometry (strike, dip and slip angles), only the slip amount is linearly related to the crustal deformation and consequently tsunami waveforms. We fix the other parameters and estimate the slip distribution on the fault from geodetic and tsunami data. The observational equation is written as (SATAKE, 1993)

$$
A_{i j} \cdot x_{j}=b_{i}
$$

where $x_{j}$ is the slip amount on subfault $j, b_{i}$ is the observation (observed subsidence or tsunami waveforms) made at station $i$, and $A_{i j}$ is the Green's function from subfault $j$ at station $i$. The Green's function is the calculated crustal deformation or tsunami waveforms from a unit amount (in the present case, $1 \mathrm{~m}$ ) of slip on each subfault.

For the geodetic Green's functions, we use vertical deformation at each observation point calculated from a finite fault in an isotropic elastic body (e.g., OKADA, 

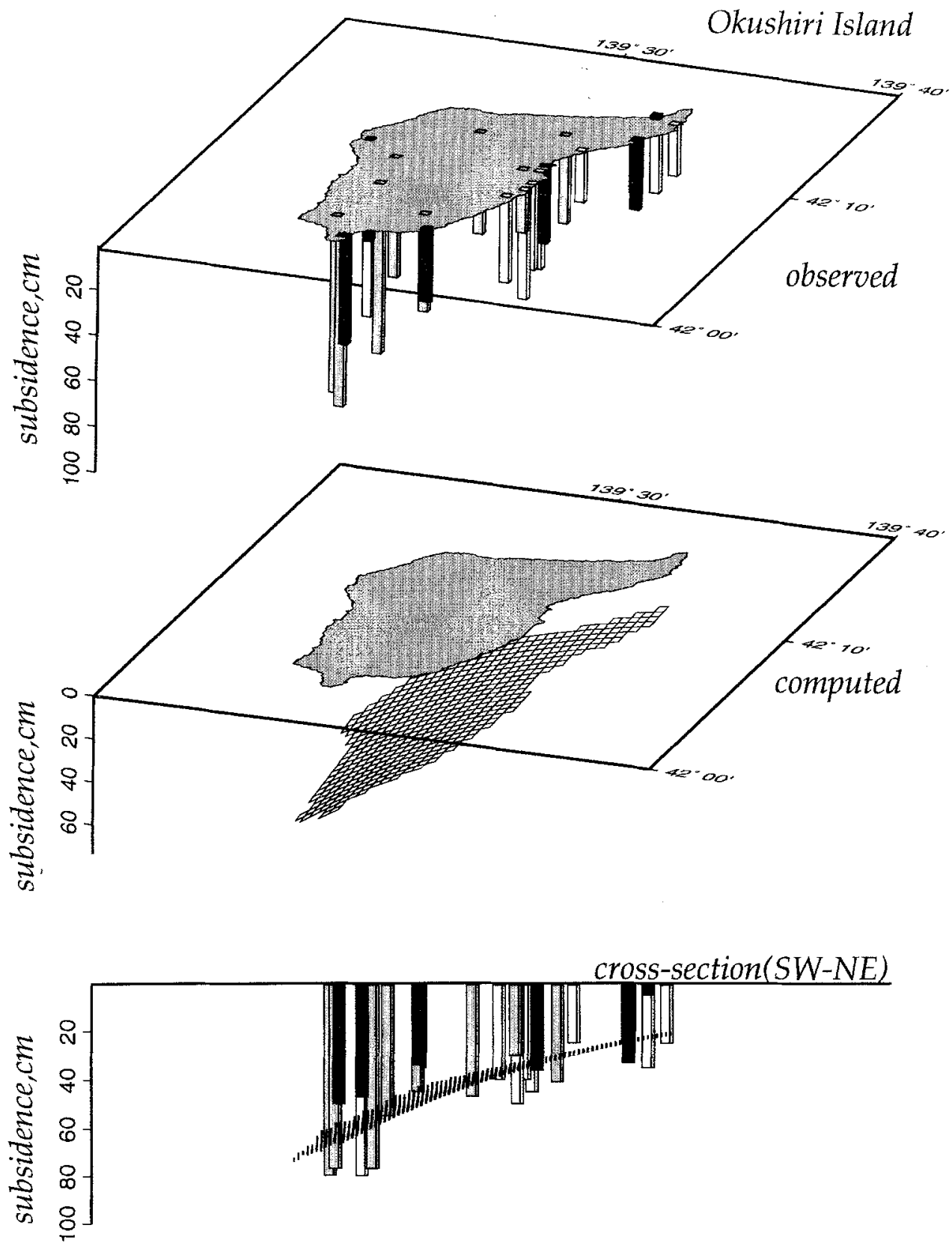

Figure 5

(top) The observed subsidence of Okushiri Island. The dark shaded bars are the data by TsuTsumi et al. (1993) based on the landmark of harbors, the lightly shaded bars are GPS data by KuMAKI et al. (1993), and the white bars are the data by KUMAKI et al. (1993) based on coastal constructions. (center) The computed subsidence from the final slip distribution on the subfaults. (bottom) Cross section along a line perpendicular to the strike of subfault $\mathrm{E}$. 
1985). For the tsunami Green's functions, we calculated the tsunami waveform at each tide gauge station from bottom deformation due to each subfault. The linear shallow water equation

$$
\frac{\partial V}{\partial t}=-g \nabla h
$$

and the equation of continuity

$$
\frac{\partial h}{\partial t}=-\nabla \cdot(d V)
$$

where $V$ is the horizontal velocity of water, $g$ is the gravitational acceleration, $h$ is the water height and $d$ is the water depth, are solved using the finite-difference method. The computational area is shown in Figure 3. The grid size is 1 minute and there are $960 \times 900$ grid points. The time step of the computation is $5 \mathrm{~s}$ to satisfy the stability condition. For other computational details, see SATAKE (1995).

We divided the source area into five subfaults as shown in Figure 2. The fault size and strike are determined in such a way that the subfaults cover the aftershock area. The size of each subfault is given in Table 1. Top edge of all the subfaults is on the ocean bottom ( $0 \mathrm{~km}$ depth). The dip angles are determined from focal mechanism solutions. The northernmost subfault, A, strikes $\mathrm{N} 20^{\circ} \mathrm{W}$ and dips $30^{\circ}$ to the east. The next two subfaults, $\mathrm{B}$ and $\mathrm{C}$, strike $\mathrm{N} 20^{\circ} \mathrm{E}$ and dip $30^{\circ}$ to the west. For the southernmost two subfaults, D and $\mathrm{E}$, we considered both the eastward dipping $\left(30^{\circ}\right)$ fault plane and the westward dipping $\left(60^{\circ}\right)$ fault plane. The strikes are the same, $\mathrm{N} 20^{\circ} \mathrm{W}$.

We applied the jackknifing technique (e.g., TICHELAAR and RUFF, 1989) to the error analysis. We inverted the data twenty times, each time randomly dropping $8 \%$ of the data. The errors for the slip amount are the standard errors of the twenty inversions multiplied by a scale factor, 3.44 in the present case.

Table 1

Heterogeneous fauls model

\begin{tabular}{ccccccc}
\hline Subfault & $\begin{array}{c}\text { Length } \\
\mathrm{km}\end{array}$ & $\begin{array}{c}\text { Width } \\
\mathrm{km}\end{array}$ & Dip & $\begin{array}{c}\text { Slip } \\
\mathrm{m}\end{array}$ & $\begin{array}{c}\text { Error } \\
\mathrm{m}\end{array}$ & $\begin{array}{c}M_{0} \\
10^{20} \mathrm{Nm}\end{array}$ \\
\hline $\mathrm{A}$ & 27 & 40 & $30^{\circ} \mathrm{E}$ & 2.26 & 0.06 & 0.85 \\
$\mathrm{~B}$ & 25 & 30 & $30^{\circ} \mathrm{W}$ & 0.52 & 0.12 & 0.14 \\
$\mathrm{C}$ & 25 & 30 & $30^{\circ} \mathrm{W}$ & 6.07 & 0.18 & 1.59 \\
$\mathrm{D}$ & 27 & 30 & $60^{\circ} \mathrm{W}$ & 3.10 & 0.13 & 0.88 \\
$\mathbb{E}$ & 35 & 30 & $60^{\circ} \mathrm{W}$ & 3.79 & 0.05 & 1.39 \\
& & & & & Total & 4.85 \\
\hline
\end{tabular}




\subsection{Inversion of Geodetic Data}

Since the geodetic data are available only on Okushiri Island, we tried to estimate the slip only on the southernmost subfault, E, which lies next to Okushiri Island. An inversion for the other faults would be very unstable (SATAKE, 1993). The result (Figure 6) demonstrated that slip amount is $9.6 \mathrm{~m}$ if the fault plane is dipping to the east, and $4.3 \mathrm{~m}$ if it dips to the west. The errors for either case are about $0.1 \mathrm{~m}$, very small, as shown in Figure 6 . The result indicates that a larger slip is required on the eastward dipping fault plane in order to explain the subsidence of Okushiri Island.

\subsection{Inversion of Tsunami Data}

The results of the inversion, using only tsunami data, are displayed in the center column of Figure 6. Both eastward and westward dipping planes of subfaults D and E yield very similar slip amounts, 3-4 $\mathrm{m}$. The dip directions of subfaults $\mathrm{D}$ and $\mathrm{E}$ affect the estimation of slip amount on subfault $\mathrm{C}$, although its dip direction is fixed to the west. The slip amount is estimated as $7.8 \mathrm{~m}$ if subfaults $\mathrm{D}$ and $\mathrm{E}$ are dipping to the west, and $6 \mathrm{~m}$ if they are dipping to the east. The slip amount on subfault $\mathrm{A}$
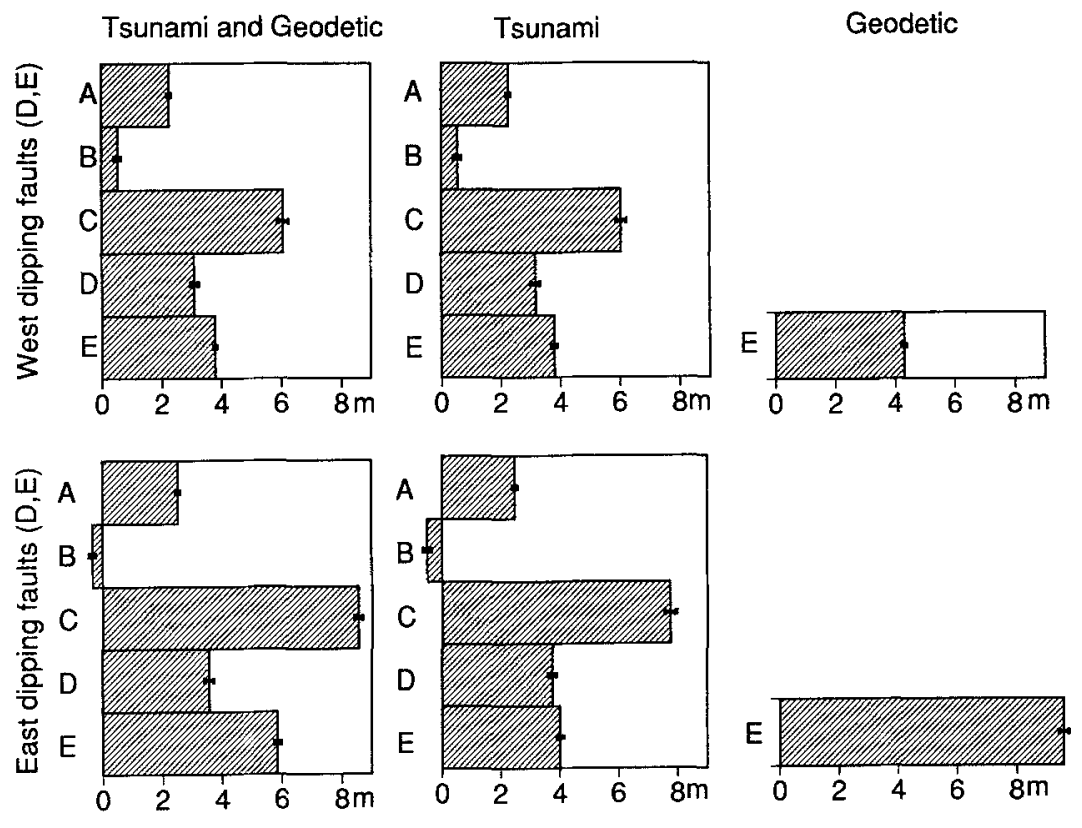

Figure 6

The results of the inversions. The top raw is for the westward dipping subfaults $D$ and $E$, the bottom raw is for the eastward dipping subfaults $D$ and $\mathrm{E}$. The dip directions of the other subfaults are fixed; subfault $A$ dips to the east and subfaults $B$ and $C$ dip to the west. The left, center, and right columns are for the joint, tsunami and geodetic inversion, respectively. The error bars are also shown. 
is about $2 \mathrm{~m}$ and it is practically zero for subfault $\mathrm{B}$, whether subfaults $\mathrm{D}$ and $\mathrm{E}$ are dipping to the east or west. Similar slip distributions for east- and westward dipping planes indicate that it is difficult to distinguish the actual fault plane from tsunami data alone.

\subsection{Joint Inversion}

We next use geodetic and tsunami data. The result of the joint inversion is shown in the left column of Figure 6. The slip amounts on subfaults A through D are very similar to those from the tsunami inversion. This is not surprising, because the geodetic data on Okushiri Island have poor control on the slip on these subfaults. The slip amount on subfault $\mathrm{E}$ is different for the eastward and westward dipping cases. It is $3.8 \mathrm{~m}$ for the westward dipping plane, but $5.9 \mathrm{~m}$ for the eastward dipping plane. For the westward dipping plane, the geodetic, tsunami, and joint inversions all give similar slip amounts, about $4 \mathrm{~m}$. For the eastward dipping plane, on the other hand, the slip estimated from the geodetic inversion is considerably larger $(9.6 \mathrm{~m})$ than that from the tsunami inversion $(4.0 \mathrm{~m})$. The joint inversion yields an amount $(5.9 \mathrm{~m})$ between these two. This indicates that the westward dipping plane provides a more stable and consistent solution. Furthermore, the variance reduction of the inversion is $81 \%$ for the westward dipping faults, whereas it is $71 \%$ for the eastward dipping faults. Hence, we prefer the solution on the westward dipping faults and conclude that the fault plane is dipping to the west at subfaults $\mathrm{D}$ and $\mathrm{E}$.

\subsection{Heterogeneous Fault Model}

Table 1 shows the final slip distribution from the joint inversion of tsunami and geodetic data, assuming that subfaults $\mathrm{D}$ and $\mathrm{E}$ are dipping to the west. Subfault $\mathrm{A}$ is dipping east and subfaults $\mathrm{B}$ and $\mathrm{C}$ are dipping west. The seismic moment on each subfault is calculated by assuming that the rigidity around the fault is $3.5 \times 10^{10} \mathrm{~N} / \mathrm{m}^{2}$. The seismic moment of subfaults $B$ and $\mathrm{C}$, near the epicenter, is $1.7 \times 10^{20} \mathrm{Nm}$, which is very similar to the moment release in the first $10 \mathrm{~s}$ $\left(2 \times 10^{20} \mathrm{Nm}\right)$ estimated from the MTRF inversion. Therefore the slips on these subfaults occurred in the initial stage of the earthquake. The total seismic moment estimated from the slip distribution is $4.9 \times 10^{20} \mathrm{Nm}$, which is slightly smaller, but very close to the total moment estimated by our CMT inversion $\left(5.5 \times 10^{20} \mathrm{Nm}\right)$. This indicates that the slip on the northern (A) and southern (D and E) subfaults occurred after those on subfaults B and C.

The tsunami waveform at each tide gauge station is computed from the final model and shown in Figure 4. The observed and computed tsunami waveforms match very well, both arrival time and amplitudes. The subsidence of Okushiri Island computed from the final slip distribution is shown in Figure 5. The bottom 
of the figure shows a cross section along the direction $\mathrm{N} 70^{\circ} \mathrm{E}$, which is perpendicular to the strike of subfaults $\mathrm{D}$ and $\mathrm{E}$. The calculated subsidence delineates the westward tilt of the island with an amount very similar to the observed.

\section{Comparison with Runup Heights}

We compute tsunami heights around Okushiri Island from the heterogeneous fault model. The computations are now made using nonlinear shallow water equations (for details see SATAKE, 1995). Figure 7 shows the initial condition, or the ocean bottom deformation from the final fault model, as well as the tsunami computational area. We repeated the computation three times using different grid sizes. They are 1 minute $(1.9 \mathrm{~km} \times 1.4 \mathrm{~km}), 20$ seconds $(0.62 \mathrm{~km} \times 0.46 \mathrm{~km})$ and 6 seconds $(0.19 \mathrm{~km} \times 0.14 \mathrm{~km})$. In each case, the tsunami propagation for $20 \mathrm{~min}$ after the earthquake is calculated and the maximum tsunami heights around Okushiri Island are recorded. We divide the Okushiri coast into small segments,

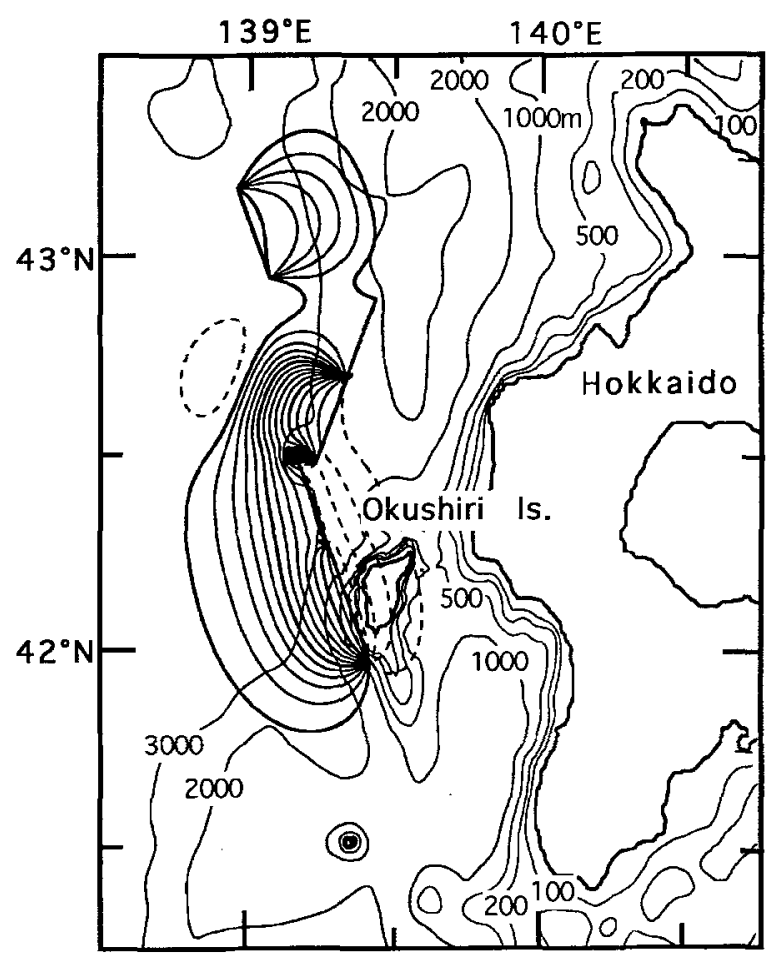

Figure 7

The vertical deformation on the ocean bottom computed from the final slip distribution on the subfaults. The solid curves indicate uplift and the dashed curves indicate subsidence. The contour interval is $20 \mathrm{~cm}$. The nonlinear tsunami computations described in Section 5 are made in the map area. 


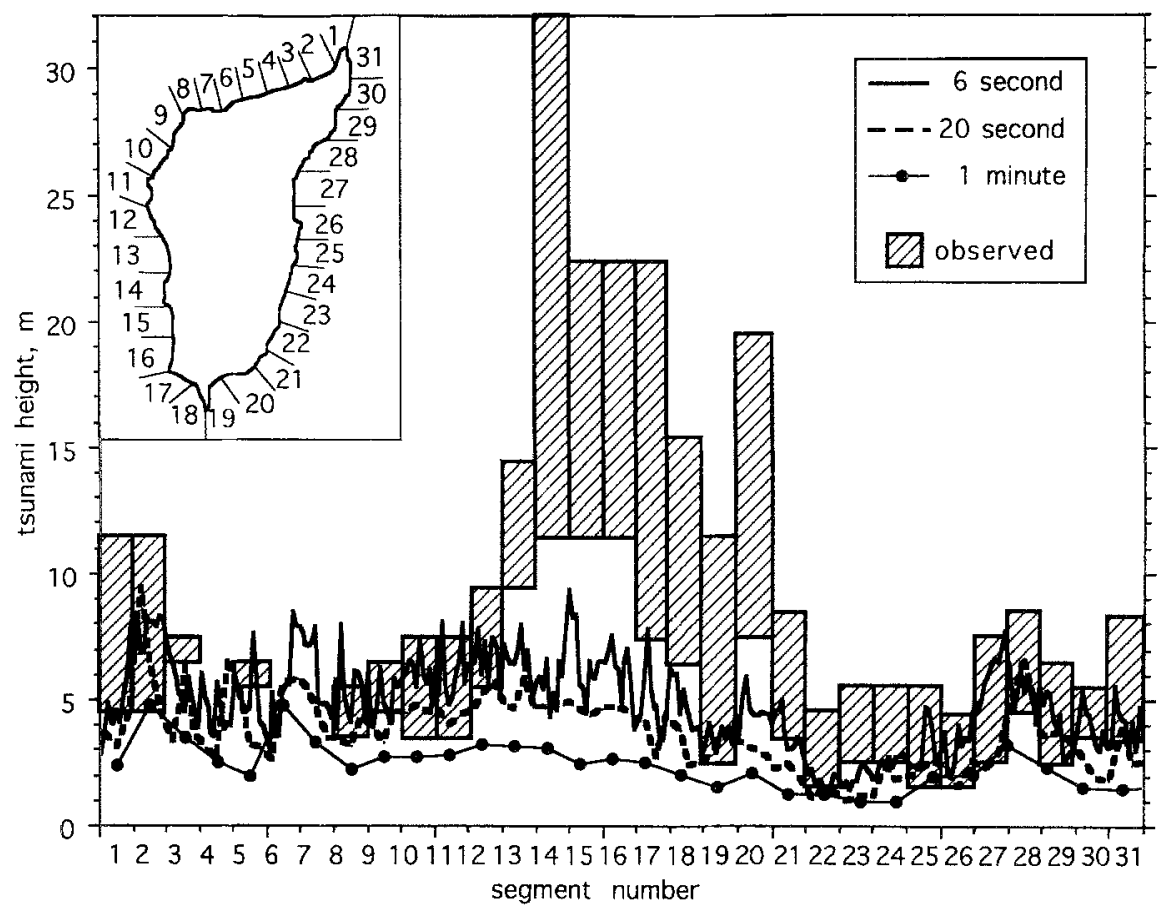

Figure 8

Comparison of the observed tsunami runup heights around Okushiri Island (striped bars) and the computed tsunami heights (curves) using the different grid sizes. The location of each segment is shown in the inset map.

each about $2 \mathrm{~km}$ long, as shown in Figure 8 . The tsunami heights in each segment are plotted in Figure 8 with the observed runup heights (HoKKAIDO TSUNAMI SURVEY GROUP, 1993).

Figure 8 shows that the computed tsunami heights are smaller than the observed runup heights. The computed heights from the different grid sizes are similar on the northern coast of Okushiri, but differ significantly on the southern coast where the observed runup heights are large. The tsunami heights computed using smaller grid sizes are larger and closer to the observed heights. The computed tsunami heights on the 6 second grids are twice as large as (100\% larger than) those on the 1 minute grids, and the tsunami heights on the 20 second grids are as much as $50 \%$ larger than those on the 1 minute grids. This is probably due to the fact that smaller grids can represent the coastal topography more accurately than the coarser grid.

The ratio of the observed runup heights to the calculated tsunami heights, or the amplification factor, therefore depends on the grid size. In the present case for Okushiri Island, it is $1-2$ for the 6 second grids, $1-3$ for the 20 second grids, and 2-4 for 1 minute grids. The result indicates that we can reproduce the observed runup heights when, and only when, we use very small grid size. 


\section{Free Oscillation of the Japan Sea}

The Japan Sea is an almost closed water basin. Tsunamis generated in the Japan Sea therefore continue persistently, because of the multiple reflections on the coasts. SATAKE and SHIMAZAKI (1988a,b) examined tsunamis from the 1964 Niigata and 1983 Japan Sea earthquakes in both wave-theoretical and normal-mode approaches. In the latter approach, they found that the 1983 Japan Sea earthquake excited all the modes equally whereas the 1964 Niigata earthquake mainly excited the regional modes. They interpreted this different excitation as due to the different water depths at the source area; the Niigata earthquake occurred beneath a continental shelf about $100 \mathrm{~m}$ deep whereas the water depth at the 1983 epicenter is about $2500 \mathrm{~m}$ (SATAKE and Shimazaki, 1988b). The Hokkaido Nansei-Oki earthquake occurred beneath the deep (about $3000 \mathrm{~m}$ ) part of the Japan Sea, similar to the 1983 event.

The characteristic period of tsunami at the source can be estimated by dividing the source size by the long-wave velocity in the source region. While the source size is similar, about $100 \mathrm{~km}$ for all these earthquakes, the long-wave velocity varies from $0.03 \mathrm{~km} / \mathrm{s}$ for a $100 \mathrm{~m}$ deep ocean to $0.17 \mathrm{~km} / \mathrm{s}$ for a $3000 \mathrm{~m}$ depth. Accordingly, the characteristic period of generated tsunamis would be about 10 min for the Hokkaido Nansei-Oki or 1983 Japan Sea events (a source in the deep ocean), but would exceed 50 min for the Niigata earthquake (a source on the continental shelf). In the following, we will examine the difference in the tsunami generation from the viewpoint of excitation of the normal modes.

\subsection{Summary of Normal Mode Approach}

Here we summarize the normal-mode theory of tsunamis; for more details, see SATAKe and SHIMAZAKI (1987, 1988b). From the linear shallow water equation (2) and the equation of continuity (3), we can derive a wave equation

$$
\frac{\partial^{2} h}{\partial t^{2}}=g \nabla \cdot(d \nabla h) .
$$

Assuming that the water height changes periodically in time, i.e.,

$$
h(x, t)=\Phi(x) e^{i \omega t}
$$

where $\Phi$ describes the spatial distribution of water height and $\omega$ is the angular frequency, we can rewrite equation (4) as the following eigenequation,

$$
\nabla \cdot(d \nabla \Phi)=\lambda \Phi \text { where } \lambda=-\omega)^{2} / g .
$$

The eigenvalue $\lambda$ is characterized by the eigenfrequency $\omega$. Equation (6) can be numerically solved for actual bathymetry using a supercomputer. SATAKE and SHIMAZAKI (1988b) computed the eigenvalues and eigenfunctions for the lowest 100 modes. The shortest eigenperiod (for mode 100) is about $50 \mathrm{~min}$. 
Tsunami waveforms can be written as a superposition of normal modes,

$$
h(x, t)=\sum_{k} C_{k} \Phi_{k}(x) e^{i \omega_{k} t}
$$

where $C_{k}$ is a coefficient, or weight, for each mode. The coefficient can be calculated from the initial water height, $h_{0}$, in the source area,

$$
C_{k}=\int_{\text {source }} h_{0}(x) \Phi_{k}(x) d x
$$

for an instantaneous source.

\subsection{Excitation of Free Oscillation by the Hokkaido Nansei-Oki Event}

We calculated the coefficients of each mode for the 1993 Hokkaido Nansei-Oki earthquake and compared them with those of the 1964 Niigata and 1983 Japan Sea events (SATAKe and ShimazaKi, 1988b) in Figure 9. The fault model was proposed by SATAKE and ABE (1982) for the Niigata earthquake, and by SATAKe (1989) for the Japan Sea earthquake. Figure 9 demonstrates that the excitation coefficients for the 1993 event are the smallest among the three. The largest coefficient is about $30 \mathrm{~cm}$ for mode 49 , whose eigenperiod is $72 \mathrm{~min}$. The coefficients for the other modes are about $10 \mathrm{~cm}$ or smaller. This indicates that the tsunami from the 1993 earthquake contained a large component with a period of $72 \mathrm{~min}$. However, the observed tsunami spectra at coastal points such as tide gauge locations are also affected by the value of eigenfunctions at the observational points (see equation (7))

The variation in excitation coefficients, (for example, the coefficient for mode 4 is $13 \mathrm{~cm}$, but only $3 \mathrm{~cm}$ for mode 5), is due to the relationship between the eigenfunction (spatial distribution of water height in each mode) and the location

of the source. As shown in Figure 10, the location of the source is near the maximum of eigenfunction for mode 4 , whereas it is on the nodal line for mode 5 . Therefore, the excitation for mode 5 is considerably smaller than that for mode 4 . The eigenfunction of mode 49 has a peak near the source (see Figure 10), which explains why the excitation coefficient of that mode is the largest.

\section{Conclusions}

The generation characteristics of the 1993 Hokkaido Nansei-Oki earthquakes are examined. The results are summarized as follows.

(1) The aftershock distribution and the joint inversion of geodetic and tsunami data indicate that the fault plane is dipping to the west except at the northern end of the source area where the fault shallowly dips to the east. The fault is shallowly 

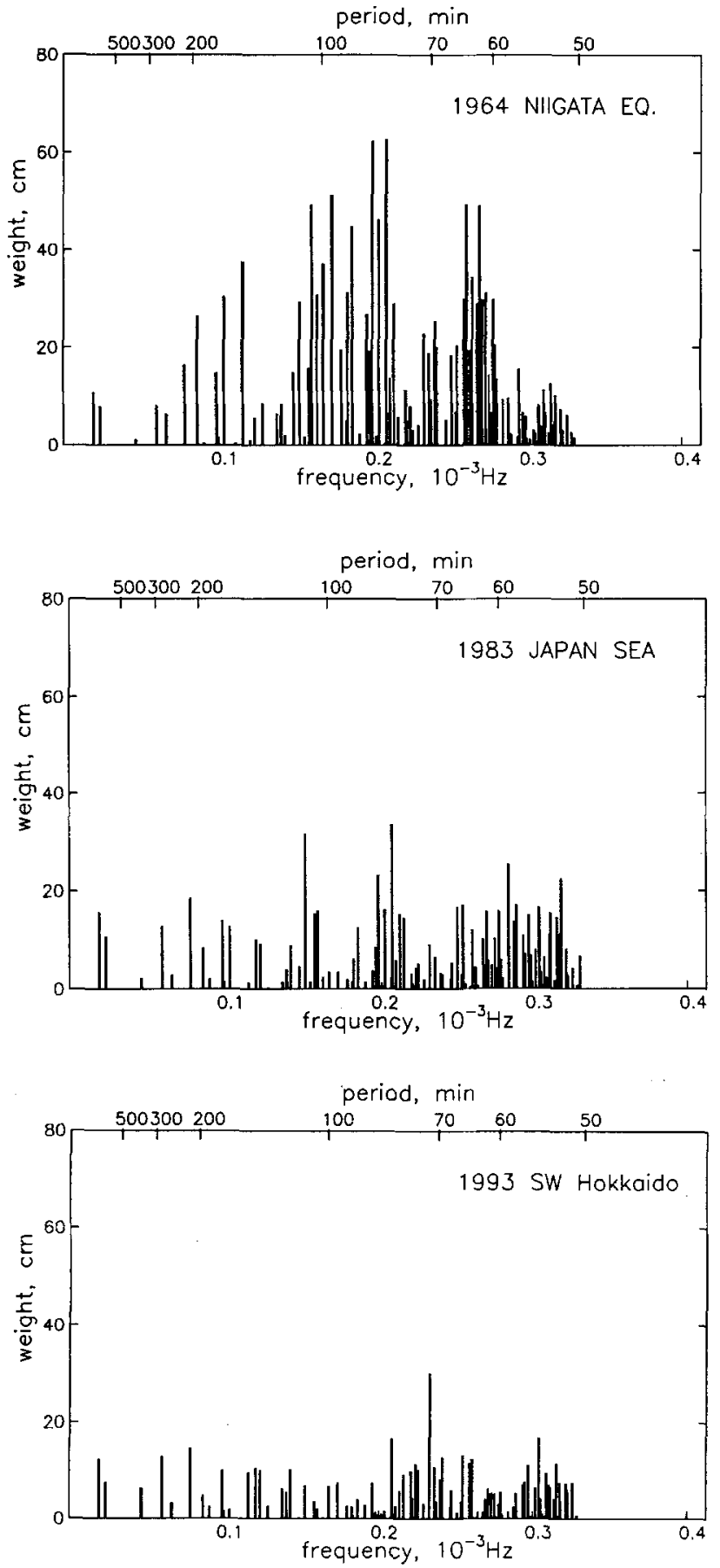

Figure 9

The excitation coefficients for each mode calculated from the 1964 Niigata earthquake (top), the 1983 Japan Sea earthquake (center) and the 1993 Hokkaido Nansei-Oki earthquake (bottom). 

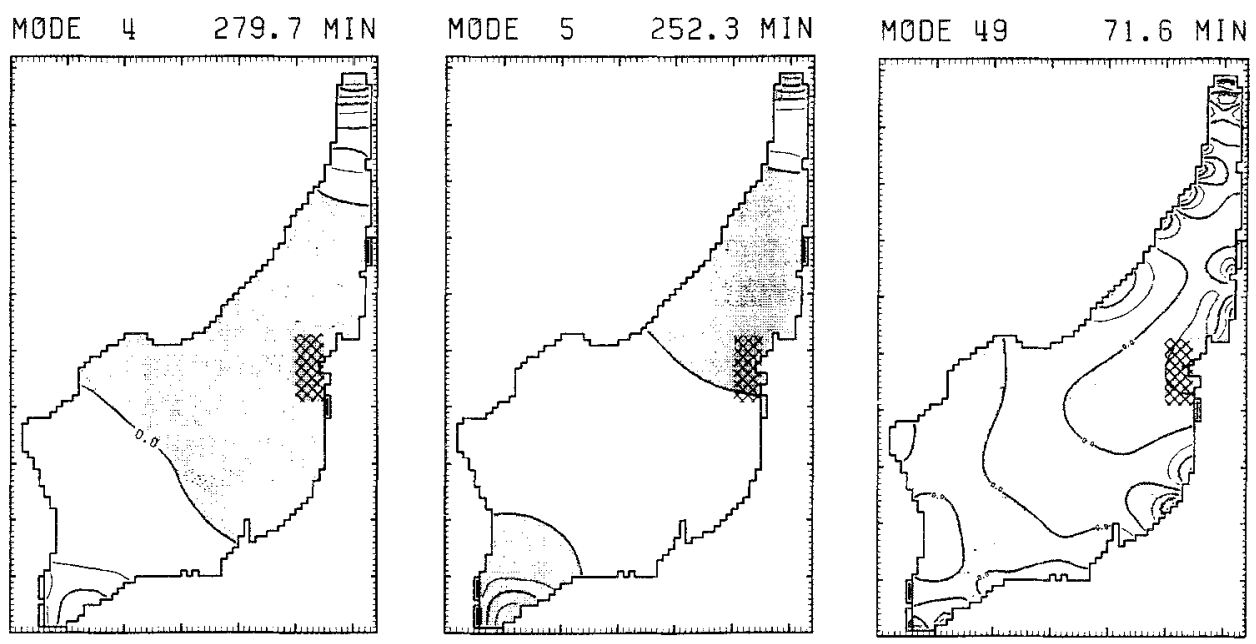

Figure 10

The eigenfunction, or the spatial distribution of water height, for modes 4,5 and 49 . Contour interval is 0.25 for the normalized eigenfunction. Open and shaded areas indicate different signs. The source area of the 1993 Hokkaido earthquake is shown by a hatched rectangle.

dipping to the west near the epicenter, but the dip is steeper on the southern part of the fault.

(2) The joint inversion indicates that the largest slip, about $6 \mathrm{~m}$, occurred just south of the epicenter. This corresponds to the moment release of the first $10 \mathrm{~s}$, as estimated from the seismic wave analysis. The slip on the northern and southern parts of the fault is smaller, 2-4 $\mathrm{m}$.

(3) Computation of tsunamis around Okushiri Island, using different grid sizes, shows that the computed tsunami heights become larger as the smaller grid size is used. This indicates that computation on small grids is necessary to reproduce the observed runup heights.

(4) The normal mode approach indicates that the tsunami excitation from the 1993 Hokkaido earthquake was smaller than the 1964 Niigata and 1983 Japan Sea earthquakes. The excitation was largest for mode 49 with a period of 72 min.

\section{Acknowledgements}

Dr. Y. Tsuji at Earthquake Research Institute, University of Tokyo, provided us with the tide gauge records. The bathymetry data were originally compiled by $M$. Okada, Meteorological Research Institute (the entire Japan Sea) and V. Gusiakov, Novosibirsk Computing Center (detailed data around Okushiri Island). This study would have been impossible to conduct without these data, and we sincerely thank them. We also thank J. Johnson for reading the manuscript and providing valuable 
comments. This work was supported by the National Science Foundation (EAR 9117800).

\section{REFERENCES}

Dziewonski, A. M., Ekström, G., and Salganik, M. P. (1994), Centroid-moment Tensor Solutions for July-September 1993, Phys. Earth Planet. Inter. 83, 165-174.

FukAo, Y., and Furumoto, M. (1975), Mechanism of Large Earthquakes along the Eastern Margin of the Japan Sea, Tectonophys. 26, 247-266.

Hokkaido Tsunami Survey Group (1993), Tsunami Devastates Japanese Coastal Region, EOS, Trans. Am. Geophys. Union 74, 417, 432.

IsHrYAMA, Y., The 1993 Hokkaido Nansei-oki earthquake, tsunami, and their damage. In Report for Grant-in-aid (05306012) (ed. Ishiyama, Y.) (Ministry of Education, Science and Culture 1994) 196 pp. 1 - 11 (in Japanese).

Kasahara, M., Kodaira, S., Motoya, Y., Takanami, T., Maeda, I., Okayama, M., Ishikawa, H., Ichiyanagi, M., Yamamoto, A., Matsumoto, S. D., Tsumura, N., OKada, T., Yabe, Y., IIDAKA, T., and HIRATA, N., Aftershock activity and distribution of the 1993 Hokkaido Nansei-oki earthquake. In Report for Grant-in-aid (05306012) (ed. Ishiyama, Y.) (Ministry of Education, Science and Culture 1994) 196 pp. 13-19 (in Japanese).

KoBAYASHI, Y. (1983), On the Initiation of Subduction of Plates, Earth Monthly 5, 510-514 (in Japanese).

Kumaki, T., Kisanuki, J., Ohtani, T., Ono, Y., and KaIIKawa, S. (1993), Vertical Seismic Crustal Movement of the 1993 Hokkaido-Nansei-oki Earthquake Based on Coastal Landform Changes in the Okushiri Island, West of Hokkaido, Japan, Prog. Abst. Seism. Soc. Japan 2, 63.

Nakamura, K. (1983), Possible Nascent Trench Along the Eastern Japan Sea as the Convergent Boundary between Eurasian and North American Plates, Bull. Earthq. Res. Inst. Univ. of Tokyo 58, $71 \mathrm{l}-722$ (in Japanese).

OKada, Y. (1985), Surface Deformation due to Shear and Tensile Faults in a Half-space, Bull. Seismol. Soc. Am. 75, 1135-1154.

SATAKE, K. (1986), Re-examination of the 1940 Shakotan-oki Earthquake and the Fault Parameters of the Earthquakes along the Eastern Margin of the Japan Sea, Phys. Earth Planet. Inter. 43, 137-147.

SATAKE, K. (1989), Inversion of Tsunami Waveforms for the Estimation of Heterogeneous Fault Motion of Large Submarine Earthquakes: 1968 Tokachi-oki and 1983 Japan Sea Earthquakes, J. Geophys. Res. 94, 5627-5636.

SATAKE, K. (1993), The Depth Distribution of Coseismic Slip along the Nankai Trough, Japan, from Joint Inversion of Geodetic and Tsunami Data, J. Geophys. Res. 98, 4553-4565.

SATAKE, K. (1995), Linear and Nonlinear Computations of the 1992 Nicaragua Earthquake Tsunamis, Pure and Appl. Geophys. 144, 455-470.

SATAKE, K., and ABE, K. (1983), A Fault Model for the Niigata, Japan, Earthquake of June 16, 1964, J. Phys. Earth. 31, 217-223.

SATAKE, K., and SHIMAZAKI, K. (1987), Computation of Tsunami Waveforms by a Superposition of Normal Modes, J. Phys. Earth. 35, 409-414.

Satake, K., and ShimAzaki, K. (1988a), Free Oscillation of the Japan Sea Excited by Earthquakes. I. Observation and Wave-theoretical Approach, Geophys. J. 93, 451-456.

SATAKE, K., and ShimAZAKi, K. (1988b), Free Oscillation of the Japan Sea Excited by Earthquakes. II. Modal Approach and Synthetic Tsunamis, Geophys. J. 93, 457-463.

Seno, T., and Sakurai, T. (1993), Can the Okhotsk Plate be Discriminated from the North American Plate? EOS, Trans. Am. Geophys. Union 74, Fall Meeting Supplement, 585.

Shuto, N., and Matsutomi, H. (1995), Field Survey of the 1993 Hokkaido Nansei-oki Earthquake Tsunami, Pure and Appl. Geophys. 144, 649-663.

SipkIN, S. A. (1994), Rapid Determination of Global Moment-tensor Solutions, Geophys. Res. Lett. 2I, $1667-1670$. 
Tanioka, Y., Ruff, L. J., and Satake, K. (1993), Unusual Rupture Process of the Japan Sea Earthquake, EOS, Trans. Am. Geophys. Union 74, 377, 379-380.

TAniokA, Y., SATAKe, K., and RufF, L. J. (1995), Total Analysis of the Hokkaido Nansei-oki Earthquake Using Seismological, Tsunami and Geodetic Data, Geophys. Res. Lett. 22, 9-12.

TrChelaAR, B. W., and RUFF, L. J. (1989), How Good are our Best Models? Jackknifing, Bootstrapping and Earthquake Depth, EOS, Trans. Am. Geophys. Union 70, 593, 605-606.

Tsutsumi, A., Shimamoto, T., Miyawaki, M., Sato, H., Kawamoto, E., and Tanaka, J. (1993), Subsidence of the Okushiri Island Caused by the Southwest-off Hokkaido Earthquake, Prog. Abst. Seismol. Soc. Japan 2, 62.

(Received August 29, 1994, revised March 6, 1995, accepted March 16, 1995) 